\title{
Comparative investigation of the effects of specific antigen-sensitized DC-CIK and DC-CTL cells against B16 melanoma tumor cells
}

\author{
PENG-TAO REN $^{1}$ and YUAN ZHANG ${ }^{2}$ \\ ${ }^{1}$ Department of Anus and Intestine Surgery and ${ }^{2}$ Electrocardiogram Room, \\ The Second Hospital of Hebei Medical University, Shijiazhuang, Hebei 050000, P.R. China
}

Received December 24, 2015; Accepted December 7, 2016

DOI: $10.3892 / \mathrm{mmr} .2017 .6175$

\begin{abstract}
The use of personalized adoptive immunotherapy as a potential novel approach is promising in the treatment of tumors resistant to conventional therapies. In the present study, dendritic cell (DC)-cytokine-induced killer (CIK) and DC-cytotoxic lymphocyte (CTL) cells were cultured to examine their phenotype, proliferation and cytotoxicity against B16 melanoma tumor cells. In addition, comparative investigations of the effect of specific antigen-sensitized DC-CIK and DC-CTL cells against B16 melanoma tumor cells were performed in vitro and in vivo. The results showed that the phenotypes of the co-cultured cells were altered, and DCs promoted DC-CIK cell and DC-CTL cell differentiation and maturation in vitro. Lactate dehydrogenase cytotoxic analysis indicated that the cytotoxicity increased as the effector to target ratio increased between 10:1 and 40:1, and the cytotoxic effect towards B16 melanoma cells by DC-CTL cells was significantly higher, compared with that of DC-CIK cells. To further examine the antineoplastic efficacy of DC-CIK and DC-CTL cells in vivo, the present study performed tail-intravenous injection of DC-CIK cells and DC-CTL cells, which attenuated B16 melanoma cell-engrafted tumor growth, induced $G_{0} / G_{1}$ cell cycle arrest and accelerated cell apoptosis. Taken together, these results suggested that the use of DC-CTL or DC-CIK cell therapy as a personalized adoptive immunotherapy may regulate immune status and inhibit tumor growth in vivo. In addition, the experiments indicated that DC-CTL cells offer superior antineoplastic activity, compared with DC-CIK cells against B16 melanoma tumor cells.
\end{abstract}

Correspondence to: Dr Yuan Zhang, Electrocardiogram Room, The Second Hospital of Hebei Medical University, 215 Peaceful West Road, Shijiazhuang, Hebei 050000, P.R. China E-mail: sh_zhangy@163.com

Key words: dendritic cell-cytokine-induced killer, dendritic cell-cytotoxic lymphocyte, melanoma, immunotherapy

\section{Introduction}

Malignant melanomas represent a refractory disease, the incidence and mortality rates of which have been steadily increasing worldwide $(1,2)$. Melanomas, particularly advanced melanomas, are not sensitive to traditional therapeutic regimens, including surgery, radiation or chemotherapy, which are usually accompanied by adverse side effects. Therefore, alternative therapeutic regimens with improved effectiveness against malignant melanomas are urgently required. Among novel developments, immunotherapy-based approaches are promising and have become a focus; they have emerged as an effective treatment option for patients with malignant tumors $(3,4)$. As is already known, melanoma is one of the most immunogenic types of cancer. Previous studies have indicated that numerous melanoma-specific antibodies and lymphocytes are present in patients with melanoma, which show responsiveness to immune-stimulating agents $(2,5,6)$. However, immune evasion mechanisms are in existence in the tumor microenvironment (7). Novel immunotherapeutic methods may offer the potential to prevent tumor recurrence, increase progression-free survival rates and improve the quality of life of patients with melanoma.

In previous reports, the immunotherapeutic use of dendritic cell (DC) vaccines, cytotoxic lymphocyte (CTL) cells and cytokine-induced killer (CIK) cells have shown promising outcomes in the improvement of cancer therapy $(8,9)$. Immunotherapy, particularly DCs co-cultured with CIK cells (DC-CIK) therapy, has been widely investigated and applied as an important option in the treatment of non-small-cell lung cancer (NSCLC) (10). In addition, DC-CIK cell-based immunotherapy is one of the most effective tools to eliminate residual cancer cells, and is well-tolerated with a high level of compliance (11). Increasing evidence suggests that DC-CIK cell therapy is widely used in advanced colorectal cancer (12), NSCLC (10) and liver cancer (13). DCs, major antigen-presenting cells, capture and process tumor-associated antigens. DCs also activate antigen-specific CTL cells and induce antitumor immune responses (14). However, to the best of our knowledge, there have been no reports on whether DC-CIK or DC-CTL possess antitumor activity in melanomas. 
In the present study, DC-CTL and DC-CIK cells were cultured to examine their effects on phenotype, proliferation and cytotoxicity against B16 melanoma tumor cells. In addition, comparative investigations on the effects of specific antigen-sensitized DC-CIK and DC-CTL cells against B16 melanoma tumor cells were performed in vitro and in vivo.

\section{Materials and methods}

Animal tumor model and preparation of DC-CTL cells and DC-CIK cells. Female C57BL/6 mice (8-week-old) were purchased from Hebei Medical University (Shijiazhuang China). All animals ( $\mathrm{n}=60,15-20 \mathrm{~g}$ ) were given free access to food and tap water and were caged individually under controlled temperature $\left(25 \pm 2^{\circ} \mathrm{C}\right)$ and humidity $(55 \pm 5 \%)$ with an artificial $12 \mathrm{~h}$ light/dark cycle) in accordance with the animal care and use committee of Heibei Medical University.

The present study was approved by the ethics committee of Heibei Medical University.

B16 melanoma cells were purchased from the Chinese Academy of Sciences Cell Bank (Shanghai, China) and cultured in RPMI 1640 (Gibco; Thermo Fisher Scientific, Inc., Waltham, MA, USA), which contained $10 \%$ fetal calf serum (Gibco; Thermo Fisher Scientific, Inc.), 10\% L-glutamine, $0.5 \%$ penicillin/streptomycin, $10 \%$ nonessential amino acids and $10 \%$ pyruvate, in a $5 \% \mathrm{CO}_{2}$ atmosphere and incubated at $37^{\circ} \mathrm{C}$. The backs of the mice were shaved completely, and a subcutaneous injection of $5 \times 10^{6}$ B16 melanoma cells was administered to the back. Mice were selected for ablation when the diameter of the tumor ranged between 5 and $10 \mathrm{~mm}$, and was approximately round in shape. Mice were sacrificed by intraperitoneal injection of sodium pentobarbital (2\%, $100 \mathrm{mg} / \mathrm{kg}$, Sigma-Aldrich; Merck Millipore, Darmstadt, Germany), and blood samples were collected from heart for separating PBMCs.

DC-CIK cells and DC-CTL cells were generated from peripheral blood mononuclear cells (PBMCs) of mice. Briefly, PBMCs were isolated from whole blood samples from mice using Ficoll density gradient centrifugation at $2,000 \times \mathrm{g}$ for $20 \mathrm{~min}$ at $4^{\circ} \mathrm{C}$ using commercial lymphocyte separation medium (Sigma-Aldrich; Merck Millipore). CIKs at a density of $2 \times 10^{5} /$ well were mixed and co-cultured with antigen-unpulsed DCs for 3 days. Additionally, CIKs were cultured in $4 \mathrm{X} 40 \mathrm{ml}$ serum-free medium supplemented with $1,000 \mathrm{U} / \mathrm{ml}$ interleukin-2 (IL-2), $5 \mu \mathrm{g} / \mathrm{ml} \mathrm{CD} 3$ monoclonal human anti-mouse antibodies (cat. no. GMP-A089; 1:500), $12.5 \mu \mathrm{g} / \mathrm{ml}$ RetroNectin (Novoprotein, Shanghai, China) and $1,000 \mathrm{U} / \mathrm{ml}$ interferon- $\gamma$ (IFN- $\gamma$; Novoprotein), which had been induced and cultured for 14 days at $37^{\circ} \mathrm{C}$. Subsequently, $\sim 2 \times 10^{6}$ DCs were harvested and co-cultured with T cells $\left(\sim 2 \times 10^{7}\right.$ cells) at a DC/T cell ratio of $1: 10$ for another 4 days to induce antigen-specific CTL cells, which were stimulated with CD3 monoclonal antibody $(50 \mathrm{ng} / \mathrm{ml}$; Novoprotein), pre-coated onto plastic plates and amplified by IL-2 (500 IU/ml; Novoprotein).

The C57BL/6 mice were randomly divided into three groups, as mentioned above. In total, $10^{6} \mathrm{DC}$-CIK cells or DC-CTL cells in $0.2 \mathrm{ml}$ PBS, or $0.2 \mathrm{ml}$ PBS, were administered intravenously into the tail of the mice in the respective groups.
Morphologic observation and cellular phenotype analysis. Morphological alterations of the DCs were observed by scanning and transmission electron microscopy following culture of the DCs for 7 days. Using flow cytometry (FCM), their phenotype molecules, CD80 ${ }^{+}, \mathrm{CD}^{2} 6^{+}$and HLA-DR ${ }^{+}$, were measured and recorded. Subsequently, the DC-CIK and DC-CTL cells were collected following 14 days of cultivation, and the expression of surface markers, $\mathrm{CD}^{3+} \mathrm{CD}^{56+}$ and $\mathrm{CD}^{3+} \mathrm{CD}^{8+}$, were examined and recorded.

Cytotoxicity towards tumor cells in vitro. The cytotoxic activity of DC-CIK cells and DC-CTL cells were assayed using calcein-AM (cat. no. 17783; Sigma-Aldrich; Merck Millipore) according to the manufacturer's protocol. Briefly, CAM media was prepared by diluting calcein-AM stock solution $(1 \mathrm{mg} / \mathrm{ml}$ in DMSO) with PBS. Prewashed B16 melanoma cells were resuspended in the CAM media $\left(10^{6}\right.$ cells $\left./ \mathrm{ml}\right)$ and incubated at $37^{\circ} \mathrm{C}$ for $1 \mathrm{~h}$ with occasional shaking. The DC-CIK cells or DC-CTL cells were resuspended with PBS at $1 \times 10^{6}$ cells $/ \mathrm{ml}$, and $200 \mu \mathrm{l}$ of the DC-CIK cells or DC-CTL cells were added into each well containing B16 melanoma cells in a U-bottom 96-well plate. The effector to target (E:T) ratio ranged between 10:1 and 40:1 (10:1, 20:1 and 40:1).

Measurements of CCL19 and CCL22 activity. The activities of CCL19 (cat. no. SBJ-M0271) and CCL22 (cat. no. SBJ-M0267) were assessed ELISA kits (Nanjing Senbeijia Biological Technology Co., Ltd., Nanjing, China). The treated cells were collected at each time point and washed with PBS. The supernatants were collected and measured to determine protein concentration.

Detection of apoptosis using FCM. The apoptotic cells were differentiated from viable or necrotic cells by the combined application of Annexin V-FITC and propidium iodide (PI; BD Biosciences, Franklin Lakes, NJ, USA). The samples were washed with PBS twice and adjusted to a concentration of $1 \times 10^{6}$ cells $/ \mathrm{ml}$ with $4^{\circ} \mathrm{C}$ PBS. Falcon tubes $(12 \times 75 \mathrm{~mm}$; polystyrene round-bottom) were used in the experiment, into each of which $100 \mu 1$ of suspension was added. Subsequently, $10 \mu \mathrm{l}$ of Annexin V-FITC and $10 \mu \mathrm{l}$ PI $(20 \mu \mathrm{g} / \mathrm{ml})$ were added into the labeled tubes and incubated for at least $20 \mathrm{~min}$ at room temperature in the dark. Following incubation, $400 \mu \mathrm{l}$ of PBS binding buffer was added to each tube without washing and analyzed using FCM (BD Biosciences) within $30 \mathrm{~min}$.

Detection of morphological alterations in solid tumors using transmission electron microscopy. Uranyl acetate and lead citrate staining of the cells were performed to detect morphological alterations. Briefly, solid tumors were digested with pancreatin and fixed with $3 \%$ glutaraldehyde precooled in $4^{\circ} \mathrm{C}$ for $2 \mathrm{~h}$. To obtain ultrathin sections of copper, the cells were washed once with PBS, fixed with $1 \%$ osmic acid for $1 \mathrm{~h}$, dehydrated using acetone and embedded in epoxide resin. Following staining with uranyl acetate and lead citrate, the sections $(100 \mathrm{~nm})$ were examined under a Hitachi-800 transmission electron microscope (Hitachi, Ltd., Tokyo, Japan).

Western blot analysis. To investigate alterations in the expression levels of caspase 3 and caspase 9 in the B16 melanoma 
cells and solid tumors, the B16 melanoma cells samples were clarified by centrifugation at 7,500 x $g$ for $10 \mathrm{~min}$ at $4^{\circ} \mathrm{C}$ and protein concentrations were determined using a BCA Protein Assay kit. The B16 melanoma cells and solid tumors were homogenized and extracted in NP-40 buffer, followed by $10 \mathrm{~min}$ boiling for denaturing and centrifugation at $12,000 \mathrm{xg}$ for $10 \mathrm{~min}$ at $4^{\circ} \mathrm{C}$ to obtain the supernatant. The equal quantities of protein $(50 \mu \mathrm{g} /$ lane $)$ were loaded on $8 \%$ gels, followed by being blotted onto polyvinylidene fluoride membranes using a wet transfer method. The membranes were blocked with 5\% non-fat milk in PBST for $4 \mathrm{~h}$ at room temperature and then incubated with primary antibodies, caspase-3 (cat. no. sc-1224, 1:1,000) and caspase-9 (cat. no. sc-133109, 1:1,000; all Santa Cruz Biotechnology, Inc., Dallas, TX, USA), in PBST overnight at $4^{\circ} \mathrm{C}$. The membranes were washed three times with PBST for $5 \mathrm{~min}$ and then incubated in secondary antibody donkey anti-goat IgG (1:10,000; cat. no. sc-2020) and goat anti-rabbit IgG (1:10,000; cat. no. sc-2004; all Santa Cruz Biotechnology, Inc.) with 5\% PBST for $2 \mathrm{~h}$ at room temperature. The membranes were washed and detected using ECL (GE Healthcare Life Sciences, Chalfont, UK), and were exposed on Kodak radiographic film (Kodak, Rochester, NY, USA) in the dark.

Statistical analysis. The results are expressed as the mean \pm standard deviation. All statistical analyses were performed using PRISM version 5.0 (GraphPad Software, Inc., La Jolla, CA, USA). Inter-group differences were analyzed using one-way analysis of variance. $\mathrm{P}<0.05$ was considered to indicate a statistically significant difference.

\section{Results}

In vitro differentiation of DCs and phenotypic analysis of cultured mature DC-CIK and DC-CTL cells. As shown in Fig. 1A, the DCs were generated from PBMCs obtained from 8 -week-old female C57BL/6 mice. The phenotypes of the co-cultured cells were analyzed using FCM to detect whether co-culture affected the DC-CIK and DC-CTL cell differentiation and maturation in vitro. The results demonstrated that the expression levels of $\mathrm{CD}^{+} 0^{+}, \mathrm{CD} 86^{+}$and $\mathrm{HLA}-\mathrm{DR}^{+}$were significantly increased in the DC-CIK and DC-CTL cells, compared with the control group. However, no significant differences were observed in the expression levels of $\mathrm{CD}^{+} 0^{+}$, $\mathrm{CD}^{2} 6^{+}$or HLA-DR ${ }^{+}$between the DC-CIK cells group and the DC-CTL cells group (Fig. 1B). Subsequently, the proportions of $\mathrm{CD}^{3+} \mathrm{CD}^{8+}$ and $\mathrm{CD}^{3+} \mathrm{CD}^{56+}$ cells were found to be significantly higher in the DC-CIK and DC-CTL cells, compared with the control group. The proportions of $\mathrm{CD}^{3+} \mathrm{CD}^{8+}$ and $\mathrm{CD}^{3+} \mathrm{CD}^{56+}$ cells were also significantly higher in the DC-CTL cells, compared with the DC-CIK cells (Fig. 1C).

Cytotoxic activity of DC-CIK and DC-CTL cells against B16 melanoma cells. In the LDH cytotoxic analysis, B16 melanoma cells were used as the target cells at various E:T ratios $(10: 1,20: 1$ and 40:1) to evaluate the specific cytotoxic activity. The results indicated that the cytotoxicity increased as the E:T ratio increased between 10:1 and 40:1. However, the cytotoxic effect of the DC-CIK group and DC-CTL group were significantly different $(\mathrm{P}<0.05)$, with the cytotoxic effects
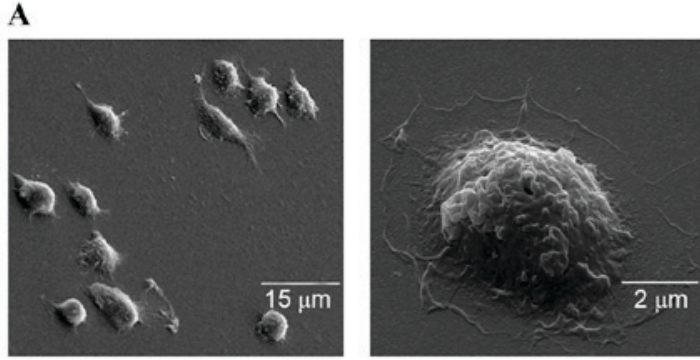

B

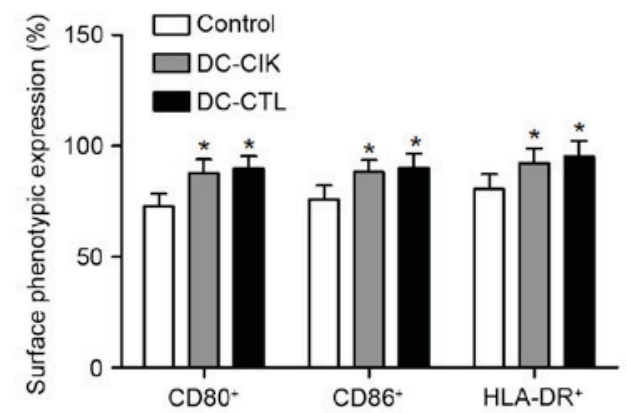

C

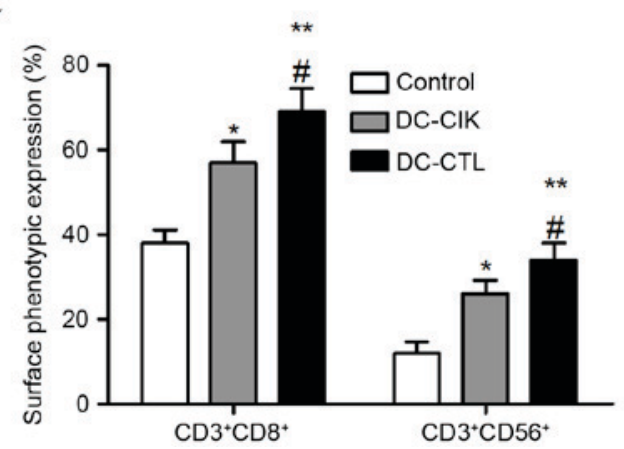

Figure 1. (A) Scanning electron microscope micrographs of DCs cultured for 7 days. (B) Cell surface markers $\left(\mathrm{CD} 80^{+}, \mathrm{CD} 86^{+}\right.$and $\left.\mathrm{HLA}-\mathrm{DR}{ }^{+}\right)$were detected in mature DCs or co-cultured cells using flow cytometry. (C) Flow cytometric analysis of phenotype $\left(\mathrm{CD}^{3+} \mathrm{CD}^{8+}\right.$ and $\left.\mathrm{CD}^{3+} \mathrm{CD}^{56+}\right)$ of mature DCs or co-cultured cells. ${ }^{*} \mathrm{P}<0.05$ and ${ }^{* *} \mathrm{P}<0.01$, vs. control group; ${ }^{*} \mathrm{P}<0.05$, vs. DC-CIK group. Data are presented as the mean \pm standard deviation of three independent experiments. DC, dendritic cell; CIK, cytokine-induced killer; CTL, cytotoxic lymphocyte.

on B16 melanoma cells by DC-CTL cells being significantly higher, compared with that by DC-CIK cells (Fig. 2A). Subsequently, the present study examined whether DC-CIK cells and DC-CTL cells regulated cell death in the B16 melanoma cell lines through an apoptotic mechanism. Following incubation with the DC-CIK cells of DC-CTL cells at the E:T ratio of 40:1, the protein levels of caspase 3 and caspase 9 were measured using western blot analysis. The results showed that the protein levels of caspase 3 and caspase 9 were increased in the B16 melanoma cells in the presence of DC-CIK cells or DC-CTL cells, respectively. However, the protein levels of caspase 3 and caspase 9 in the B16 melanoma cells co-cultured with DC-CTL cells were significantly higher, compared with those co-cultured with DC-CIK cells (Fig. 2B).

ELISA for chemokines CCL19 and CCL22. CCL19 is expressed in secondary lymphoid organs and the thymus, 
A

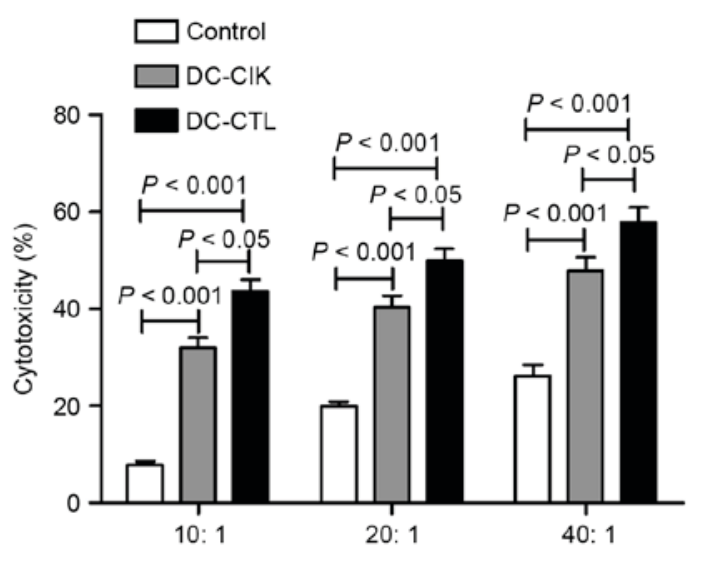

B
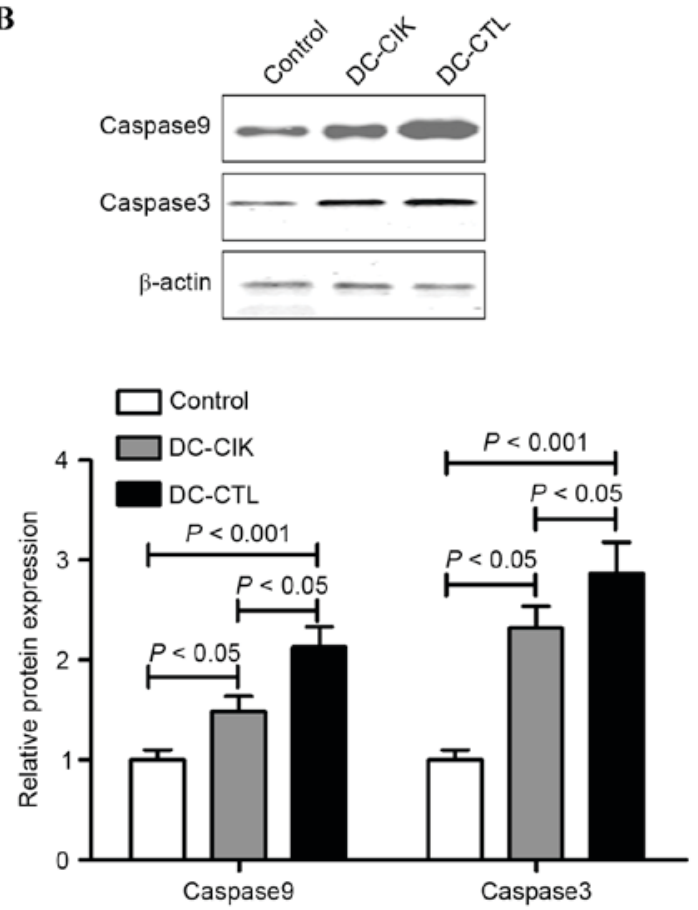

Figure 2. (A) Cytotoxicity was measured using a lactate dehydrogenase assay in B16 melanoma cells with different effector to target ratios. (B) Protein expression levels of caspase 3 and caspase 9 were measured using western blot analysis of B16 melanoma exposed to DC-CIK cells or DC-CTL cells for 24 h. DC, dendritic cell; CIK, cytokine-induced killer; CTL, cytotoxic lymphocyte.

and can induce DCs to migrate from the peripheral region to areas of $\mathrm{T}$ cell accumulation in lymphoid organs, inducing $\mathrm{T}$ helper 1 and $\mathrm{T}$ cells to form an immune response. CCL22 is expressed in the spleen, peripheral blood $\mathrm{T}$ cells, and natural killer cells. In the supernatant of the monocyte-derived DCs, intact CCL22 become expressed at a high level and produces intense chemotaxis for DCs (15). The expression levels of CCL19 and CCL22 in the culture supernatants of the co-cultured DC-CIK cells or DC-CTL cells were significantly higher, compared with the control group following co-culture for $6 \mathrm{~h}$ (Fig. 3A and B). In addition, the levels of CCL19 and CCL22 in B16 melanoma cells co-cultured with DC-CTL cells were significantly higher, compared with those co-cultured with DC-CIK cells (Fig. 3A and B).

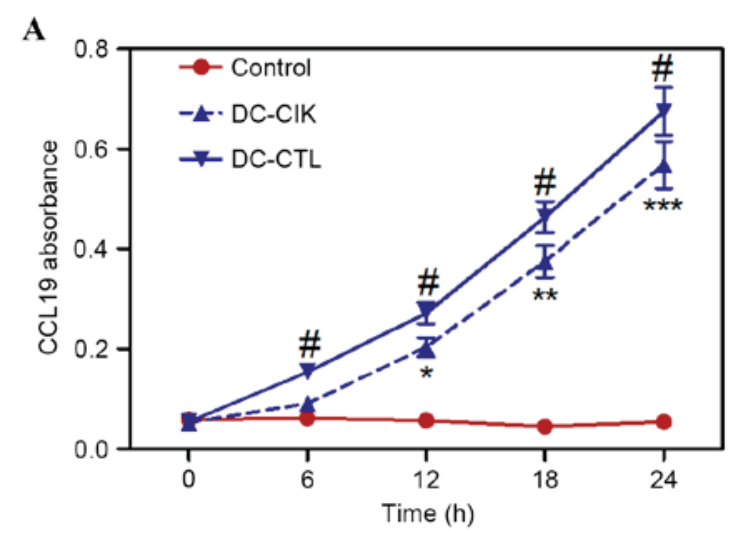

B

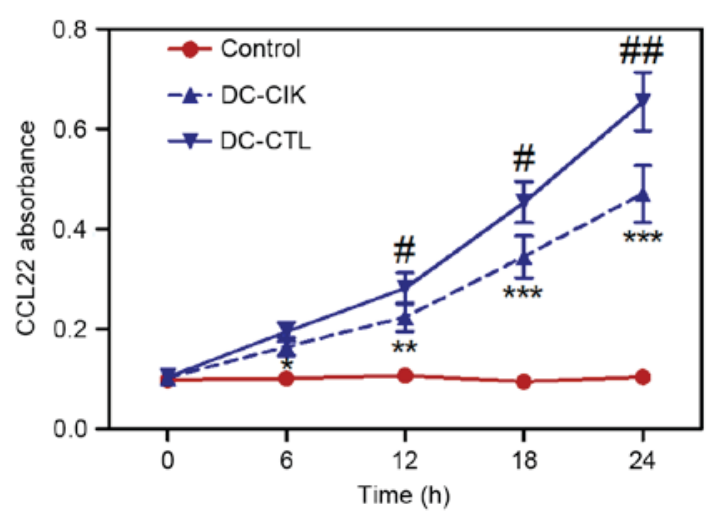

Figure 3. Levels of (A) CCL19 and (B) CCL22 at different time points were measured using an ELISA assay. ${ }^{*} \mathrm{P}<0.05,{ }^{* *} \mathrm{P}<0.01$ and ${ }^{* * *} \mathrm{P}<0.001$, vs. control group; ${ }^{\#} \mathrm{P}<0.05$ and ${ }^{\# \#} \mathrm{P}<0.01$, vs. DC-CIK group. Data are presented as the mean \pm standard deviation of three independent experiments. DC, dendritic cell; CIK, cytokine-induced killer; CTL, cytotoxic lymphocyte.

In vivo antineoplastic efficacy of DC-CIK and DC-CTL cells. In order to examine whether DC-CIK cells or DC-CTL cells can regulate B16 melanoma cell growth in vivo, the present study performed a tumor xenograft experiment. Tail-intravenous injection of DC-CIK cells and DC-CTL cells attenuated B16 melanoma cell-engrafted tumor growth in vivo. However, no significant differences between the antineoplastic efficacy of the DC-CIK and DC-CTL cells were found in vivo (Fig. 4A and B). To further investigate the antineoplastic efficacy of DC-CIK and DC-CTL cells in vivo, morphological alterations and apoptosis were measured using a transmission electron microscope and FCM. Following treatment with DC-CIK cells and DC-CTL cells, a region of the nuclear membrane domed outward with a sharp angle, the nuclei showed chromatin pyknosis and were clustered on the inner border of karyotheca, cytoplasm condensation and swelling of mitochondria were observed in the inner segment. By contrast, the nuclear membrane appeared clear and complete in the normal B16 melanoma cells (Fig. 4C). Following treatment with the DC-CIK cells or DC-CTL cells, the effect on cell-cycle distribution was determined using FCM. As shown in Table $\mathrm{I}$, an accumulation of cells in the $\mathrm{G}_{0} / \mathrm{G}_{1}$ phase was observed followed treatment of the B16 melanoma cell mouse model with DC-CIK cells and DC-CTL cells. However, no significant differences in cell-cycle distribution were found 
Table I. Effects of DC-CIK cells and DC-CTL cells on the cell cycle distribution, AI and PI in B16 melanoma cells.

\begin{tabular}{lccrrc}
\hline Group & $\mathrm{G}_{0} / \mathrm{G}_{1}$ & $\mathrm{~S}$ & \multicolumn{1}{c}{$\mathrm{G}_{2} / \mathrm{M}$} & $\mathrm{AI}$ & PI \\
\hline DC-CIK & $81.65 \pm 2.39^{\mathrm{a}}$ & $14.27 \pm 1.49^{\mathrm{a}}$ & $8.16 \pm 0.86^{\mathrm{a}}$ & $14.32 \pm 3.01^{\mathrm{a}}$ & $20.86 \pm 1.25^{\mathrm{a}}$ \\
DC-CTL & $83.17 \pm 2.57^{\mathrm{a}}$ & $15.27 \pm 1.65^{\mathrm{a}}$ & $9.02 \pm 0.95^{\mathrm{a}}$ & $15.10 \pm 2.83^{\mathrm{a}}$ & $21.37 \pm 1.58^{\mathrm{a}}$ \\
Control & $59.47 \pm 1.62$ & $14.82 \pm 0.71$ & $21.63 \pm 1.76$ & $3.58 \pm 1.26$ & $41.75 \pm 1.88$
\end{tabular}

Values are expressed as the mean \pm standard deviation ( $\mathrm{n}=5$ per group). ${ }^{\mathrm{a}} \mathrm{P}<0.05$, vs. control. $\mathrm{DC}$, dendritic cell; CIK, cytokine-induced killer; CTL, cytotoxic lymphocyte; AI, apoptotic index; PI, proliferation index.

A

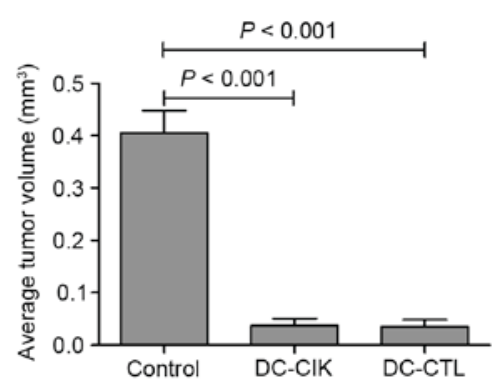

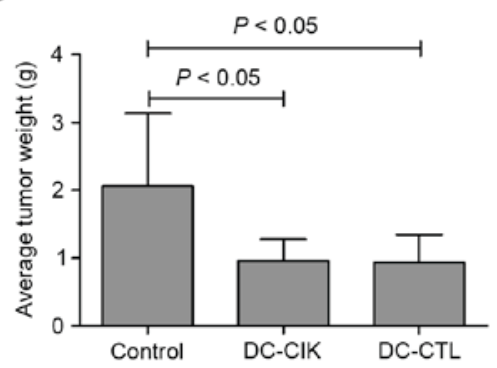

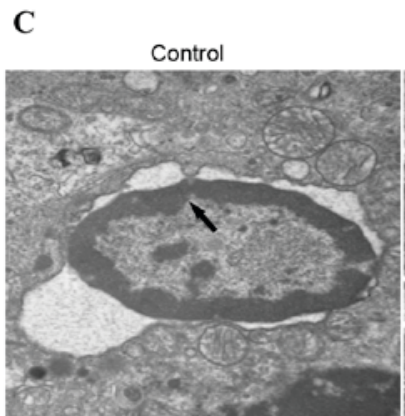

D

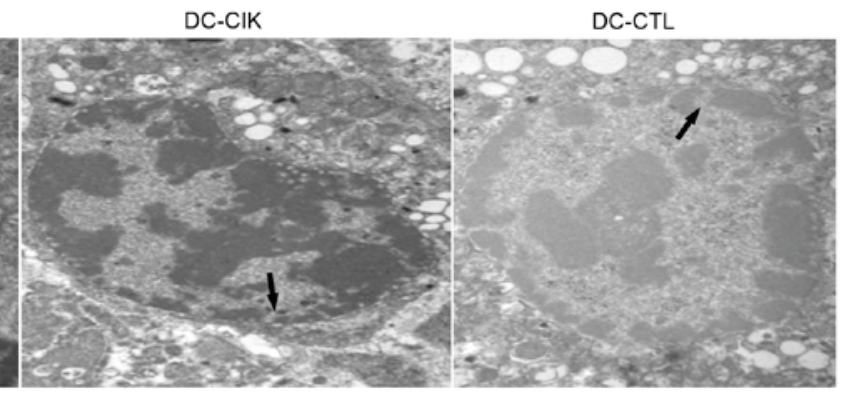

$\square$ Control

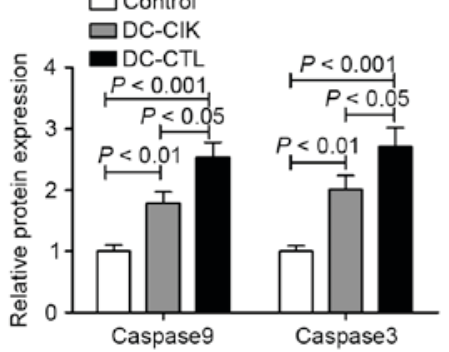

Figure 4. (A) Average tumor volume and (B) weight were evaluated at the end of the experiments ( $\mathrm{n}=10$ in each group). (C) Morphological alterations of B16 melanoma cells in the presence of DC-CIK cells or DC-CTL cells were measured under a transmission electron microscope. Magnification, x6,000. The arrows indicate the progression of the collapse of the nucleus. (D) Protein expression levels of caspase 3 and caspase 9 in the B16 melanoma tumor tissues were measured using western blot analysis. DC, dendritic cell; CIK, cytokine-induced killer; CTL, cytotoxic lymphocyte.

between the DC-CIK group and DC-CTL group. The protein levels of caspase 3 and caspase 9 were also increased in the B16 melanoma solid tumors treated with DC-CIK cells and DC-CTL cells. However, the protein levels of caspase 3 and caspase 9 in the DC-CTL group were significantly higher, compared with those in the DC-CIK group (Fig. 4D).

\section{Discussion}

The use of personalized adoptive immunotherapy as a potential novel approach is promising in the treatment of tumors resistant to conventional therapies by providing precise and optimal treatment to lower the rates of recurrence and metastasis in malignant tumors $(16,17)$. CIK cells are now considered a primary candidate for personalized adoptive immunotherapy, which have potent antiproliferative and cytotoxic capacities against tumor cells $(18,19)$. It is suggested that CIK cells are heterogeneous in vitro-expanded $\mathrm{T}$ lymphocytes with mixed natural killer (NK)-like T cells. The antitumor activity of CIK cells is predominantly due to the high proliferative and cytolytic potential of $\mathrm{CD}^{+} \mathrm{CD}^{+} 6^{+} \mathrm{NKT}$ cells (20). TLC cells are a major component of the cellular immune response and are essential cells required for antitumor immunity (21). Previous studies have indicated that DC-CTL/CIK therapy significantly reduces 
several serological tumor markers, including AFP, CA199 and CA242 in primary liver cancer, and CA724 in gastric cancer, elevates the level of $\mathrm{CD}^{+}{ }^{+} \mathrm{CD} 8^{+} \mathrm{T}$ cells in primary liver cancer and lung cancer, decreases the level of $\mathrm{CD}^{+}{ }^{+} \mathrm{CD} 4^{+} \mathrm{T}$ cells in colon cancer, primary liver cancer and lung cancer and decreases regulatory $\mathrm{T}$ cells in all types of tumor $(1,8-10)$. These results indicate that DC-CTL/CIK can promote immune functions in these patients (20). Based on these studies, the present study aimed to perform a comparative investigation of the effect of specific antigen-sensitized DC-CIK and DC-CTL cells against B16 melanoma tumor cells.

The results of the present study showed that DC-CIK cells and DC-CTL cells exhibited antineoplastic activities in vitro and in vivo. In vitro, the cytotoxicity increased as the E:T ratio increased between 10:1 and 40:1. Comparison of the cytotoxic effect between the DC-CIK group and DC-CTL group showed significant differences, in which the cytotoxic effects on B16 melanoma cells were significantly higher when exposed to DC-CTL cell co-culture, compared with DC-CIK cell culture. In addition, DC-CIK cells and DC-CTL cells regulated B16 melanoma cell growth in vivo, as tail-intravenous injection of DC-CIK cells and DC-CTL cells attenuated B16 melanoma cell-engrafted tumor growth, induced $\mathrm{G}_{0} / \mathrm{G}_{1}$ cell cycle arrest and accelerated apoptosis.

CIK cells are a cell population obtained from PBMCs stimulated with IFN- $\gamma$, IL-2 and CD3 monoclonal antibody (22). They can express the surface markers of $\mathrm{T}$ cells and NK cells, $\mathrm{CD}^{3+} \mathrm{CD}^{2} 6^{+}(23)$. In the present study, co-culture appeared to affect DC-CIK cell and DC-CTL cell differentiation and maturation in vitro, and the expression levels of $\mathrm{CD} 80^{+}, \mathrm{CD} 86^{+}$ and $\mathrm{HLA}-\mathrm{DR}^{+}$were significantly increased in the DC-CIK and DC-CTL cells. In addition, the proportion of $\mathrm{CD}^{3+} \mathrm{CD}^{8+}$ and $\mathrm{CD}^{3+} \mathrm{CD}^{56+}$ cells were found to be significantly higher in the DC-CIK and DC-CTL cells, compared with the control group. The proportion of $\mathrm{CD}^{3+} \mathrm{CD}^{8+}$ and $\mathrm{CD}^{3+} \mathrm{CD}^{56+}$ cells was also significantly higher in the DC-CTL cells, compared with the DC-CIK cells. These observations confirm and expand the findings of previous reports that $\mathrm{CD}^{+} \mathrm{CD}^{2} 6^{+}$cells show enhanced antitumor activity in the presence of DC $(8,24)$.

In conclusion, the results of the present study demonstrated that the use of DC-CTL cell or DC-CIK cell therapy, as a personalized adoptive immunotherapy, regulated the immune status and inhibited tumor growth in vivo. In addition, the experiments indicated that DC-CTL cells offer superior antineoplastic activity, compared with DC-CIK cells against B16 melanoma tumor cells. These findings provide valuable insights into the clinical curative effects of DC-CTL cell and DC-CIK cell immunotherapy, and the design of immunotherapeutic strategies for malignant tumors may be significant for the prevention of tumor growth.

\section{References}

1. Wang Y, Xu Z, Zhou F, Sun Y, Chen J, Li L, Jin H and Qian Q: The combination of dendritic cells-cytotoxic T lymphocytes/cytokine-induced killer (DC-CTL/CIK) therapy exerts immune and clinical responses in patients with malignant tumors. Exp Hematol Oncol 4: 32, 2015.

2. Ouyang Z, Wu H, Li L, Luo Y, Li X and Huang G: Regulatory T cells in the immunotherapy of melanoma. Tumour Biol 37: 77-85, 2016.
3. Brower V: Combination immunotherapy breakthrough for melanoma. Lancet Oncol 16: e318, 2015.

4. Brower V: Immunotherapy combination promising for melanomas. Lancet Oncol 16: e265, 2015.

5. Boon T, Coulie PG, Van den Eynde BJ and van der Bruggen P: Human $\mathrm{T}$ cell responses against melanoma. Annual Rev Immunol 24: 175-208, 2006.

6. Garbe C, Eigentler TK, Keilholz U, Hauschild A and Kirkwood JM: Systematic review of medical treatment in melanoma: Current status and future prospects. Oncologist 16: 5-24, 2011.

7. Fourcade $\mathbf{J}$ and Zarour HM: Strategies to reverse melanoma-induced T-cell dysfunction. Clin Dermatol 31: 251-256, 2013.

8. Chen R, Deng X, Wu H, Peng P, Wen B, Li F and Li F: Combined immunotherapy with dendritic cells and cytokine-induced killer cells for malignant tumors: A systematic review and meta-analysis. Int Immunopharmacol 22: 451-464, 2014.

9. El Ansary M, Mogawer S, Elhamid SA, Alwakil S, Aboelkasem F, Sabaawy HE and Abdelhalim O: Immunotherapy by autologous dendritic cell vaccine in patients with advanced HCC. J Cancer Res Clin Oncol 139: 39-48, 2013.

10. Wang $S$ and Wang Z: Efficacy and safety of dendritic cells co-cultured with cytokine-induced killer cells immunotherapy for non-small-cell lung cancer. Int Immunopharmacol 28: 22-28, 2015.

11. Dougan $\mathrm{M}$ and Dranoff G: Immune therapy for cancer. Annu Rev Immunol 27: 83-117, 2009.

12. Lin T, Song C, Chuo DY, Zhang H and Zhao J: Clinical effects of autologous dendritic cells combined with cytokine-induced killer cells followed by chemotherapy in treating patients with advanced colorectal cancer: A prospective study. Tumour Biol 37: 4367-4372, 2016.

13. Yu X, Zhao H, Liu L, Cao S, Ren B, Zhang N, An X, Yu J, $\mathrm{Li} \mathrm{H}$ and Ren X: A randomized phase II study of autologous cytokine-induced killer cells in treatment of hepatocellular carcinoma. J Clin Immunol 34: 194-203, 2014.

14. Banchereau J and Steinman RM: Dendritic cells and the control of immunity. Nature 392: 245-252, 1998.

15. Tan G, Zhang X, Feng H, Luo H and Wang Z: The therapeutic effect of cytokine-induced killer cells on pancreatic cancer enhanced by dendritic cells pulsed with K-ras mutant peptide. Clin Dev Immunol 2011: 649359, 2011.

16. Wayteck L, Breckpot K, Demeester J, De Smedt SC and Raemdonck K: A personalized view on cancer immunotherapy. Cancer Lett 352: 113-125, 2014.

17. Olioso P, Giancola R, Di Riti M, Contento A, Accorsi P and Iacone A: Immunotherapy with cytokine induced killer cells in solid and hematopoietic tumours: A pilot clinical trial. Hematol Oncol 27: 130-139, 2009.

18. Schmidt-Wolf IG, Negrin RS, Kiem HP, Blume KG and Weissman IL: Use of a SCID mouse/human lymphoma model to evaluate cytokine-induced killer cells with potent antitumor cell activity. J Exp Med 174: 139-149, 1991.

19. Pan Y, Tao Q, Wang H, Xiong S, Zhang R, Chen T, Tao L and Zhai Z: Dendritic cells decreased the concomitant expanded Tregs and Tregs related IL-35 in cytokine-induced killer cells and increased their cytotoxicity against leukemia cells. PLoS One 9: e93591, 2014

20. Jäkel CE and Schmidt-Wolf IG: An update on new adoptive immunotherapy strategies for solid tumors with cytokine-induced killer cells. Expert Opin Biol Ther 14: 905-916, 2014.

21. Chávez-Galán L, Arenas-Del Angel MC, Zenteno E, Chávez R and Lascurain R: Cell death mechanisms induced by cytotoxic lymphocytes. Cell Mol Immunol 6: 15-25, 2009.

22. Hishii M, Kurnick JT, Ramirez-Montagut T and Pandolfi F: Studies of the mechanism of cytolysis by tumour-infiltrating lymphocytes. Clin Exp Immunol 116: 388-394, 1999.

23. Franceschetti M, Pievani A, Borleri G, Vago L, Fleischhauer K, Golay J and Introna M: Cytokine-induced killer cells are terminally differentiated activated CD8 cytotoxic T-EMRA lymphocytes. Exp Hematol 37: 616-628.e2, 2009.

24. Wongkajornsilp A, Wamanuttajinda V, Kasetsinsombat K, Duangsa-ard S, Sa-ngiamsuntorn K, Hongeng S and Maneechotesuwan K: Sunitinib indirectly enhanced anti-tumor cytotoxicity of cytokine-induced killer cells and $\mathrm{CD}^{+}{ }^{+} \mathrm{CD} 56^{+}$ subset through the co-culturing dendritic cells. PLoS One 8: e78980,2013. 